\title{
A comparative analysis of productivity in Brazilian and Mexican manufacturing industries
}

\section{Armênio de Souza Rangel and Fernando Garcia de Freitas}

ABSTRACT

This article analyses productivity trends in Brazilian and Mexican manufacturing industries between 1995 and 2009, a period in which international competition intensified sharply. A total of 14 manufacturing industries are considered, using two methods based on: (i) the Leontief (1951) model to measure the consumption of intermediate goods used in production; and (ii) the analysis of total factor productivity (TFP). The studies performed show that manufacturing trends have diverged in the two countries. In Mexico, an increased need for imported goods and services was offset by a reduction in domestic goods and service requirements, and an increase in the TFP of production. In the case of Brazil, the fact that manufactured goods markets are more isolated from foreign trade seems to have contributed to a weak productivity performance.

Industry, industrial enterprises, manufactures, productivity, comparative analysis, input-output analysis, econometric models, Brazil University of São Paulo (usP), Brazil. armenio@usp.br

Fernando Garcia de Freitas, economic director of the Brazilian Chamber of Services and economic adviser to the Brazilian Aluminium Association (ABAL). fernando.garcia.freitas@gmail.com 


\section{I}

\section{Introduction}

Over the past two decades, the Mexican and Brazilian economies experienced profound transformations, largely driven by foreign trade. The reduction of import quotas, together with the elimination of non-tariff barriers and trade integration with neighbouring countries, radically changed the structure of the two countries' foreign trade. In manufacturing industry, Brazil and Mexico suddenly faced external competition, particularly from East Asian countries. As noted by Mesquita (2007), the emergence of China on the world industrial stage posed major challenges to the Latin American economies, because the static and dynamic productivity differentials of Chinese manufacturers place enormous constraints on the productive potential of Brazilian and Mexican manufacturing industries.

Following a lengthy growth period, the share of manufacturing industries in Brazilian and Mexican gross domestic product (GDP) fell sharply. According to the statistics and indicators database (CEPALSTAT) of the Economic Commission for Latin America and the Caribbean (ECLAC), manufacturing-industry GDP shares peaked in 1985 at 35.9\% in Brazil, and in 1988 at $27 \%$ in Mexico. In 1996, manufacturing value added had declined to just $19.6 \%$ of Mexican GDP and $14.8 \%$ of Brazilian GDP. This loss of GDP share has continued since, albeit at a slower pace: in 2011, manufactured goods represented just $17.8 \%$ of Mexico's GDP and $12.4 \%$ of Brazil's. ${ }^{1}$

This result was due mainly to the slowdown in industrial growth. Katz (2000) found that manufacturing industry output grew by $3.8 \%$ per year in Mexico and by $2.8 \%$ per year in Brazil between 1970 and 1996, but growth was slower in the period 1996-2009. Figures from the World Input-Output Database (WIOD, 2012) show that the annual growth rate of manufacturing production fell to $1.2 \%$ in Brazil and $1.6 \%$ in Mexico, in that period.

Moreover, the slackening of manufacturing productivity growth was even more serious than the decrease in its share. According to the study by Katz (2000), between 1970 and 1996, labour productivity

$\square$ The authors are grateful to an anonymous referee and to professors Ana Lélia Magnabosco and Rogério Cesar de Souza for valuable comments and suggestions made on previous versions of this article.

1 For further details, see Mesquita (2007). rose by $2.9 \%$ per year in Mexican manufacturing industry and by $1.9 \%$ per year in the same sector in Brazil. WIOD (2012) data report an increase in value added per worker of just $0.1 \%$ per year in the Mexican manufacturing industry between 1996 and 2009, and a much worse situation in Brazil, where value added per worker actually decreased by $1 \%$ per year, showing a sharply declining trend of labour productivity.

This study analyses the trend in productivity in Brazilian and Mexican manufacturing industries between 1995 and 2009, a period in which the two economies faced growing international competition. The analysis considers 14 sectors of manufacturing industry: food, beverages and tobacco; textile and textile products; leather and footwear; wood and products of wood; paper and pulp $;^{2}$ coke and refined petroleum; chemical products, plastics and rubber; non-metallic mineral products; metallurgy and metal products; machinery and equipment; electrical and optical equipments; transport equipment; and other industrial products.

The productivity trend is analysed in two ways: (i) using the Leontief (1951) model to measure the consumption of intermediate goods used in production, and (ii) through total factor productivity (TFP), which takes account of production factor requirements. The first measure of productivity defines the quantities of goods and services needed to produce one monetary unit of a given manufacture. The analysis allows for comparisons of productivity through time and space; and relative changes in productivities can be identified in the comparison between two countries over time.

Nonetheless, variations in production coefficients through time do not necessarily imply an improvement or worsening of technical and economic conditions in the industrial sector in question. Among other things, an industry's input expenses may rise because certain stages of production are outsourced. If this step is taken to enhance efficiency, the price of the goods may even fall, suggesting a reduction in output value and an apparent loss of productivity. Nonetheless, outsourcing saves on capital and labour in the final activity sector, involving an increase in TFP. In that case, a more detailed

\footnotetext{
2 The paper and pulp sector includes production by the graphics and printing industry.
} 
analysis of productivity should be complemented from the standpoint of the production factors used.

That aspect is highly relevant in the comparison between Brazil and Mexico, since both countries underwent trade liberalization which, in general, increased the share of imported goods and services in industry's intermediate consumption. Brazil also saw intensive outsourcing in manufacturing activities, owing to the rising costs of labour and social protection — processes that had been under way since the early 1990s-. Outsourcing dynamics were also impacted by the degree of economic integration, which was very different in the two countries.

This article is divided into three sections apart from this introduction. Section II compares the industrial productivity of the Brazilian and Mexican economies from the standpoint of the consumption of intermediate inputs, whereas section III analyses TFP. Lastly, section IV summarizes and comments on the results of the analysis and briefly evaluates the influence of economic liberalization on the trend of industrial productivity in the two countries.

\section{II}

\section{Input productivity}

\section{The concept of productivity in input-output analysis}

The literature on input-output analysis describes three widely used methods to evaluate technical change: (i) the direct comparison of technical coefficients; (ii) structural decomposition, and (iii) the "rowscaler" method. ${ }^{3}$ All three techniques are based on the Leontief model, and their applications use national input-output tables as data sources.

The direct comparison of technical coefficients was suggested by Leontief himself (1951) as a way to evaluate technical change. Considering the basic equation of the Leontief model, $X=(I-A)^{-1} Y=B Y$, in which $X$ is the vector of production, $Y$ is the vector of final demand and $B$ is the Leontief matrix, defined as the inverse of the difference between the identity matrix $(I)$ and the technical coefficients matrix $(A)$, the method suggested by Leontief entails directly comparing the $a_{i j}$ of two A matrices, which can differ in time or space. ${ }^{4}$ When this is applied to matrices of physical coefficients, the method admits only partial conclusions, because it is impossible to aggregate quantities to identify the characteristics of a sector, for example. Although aggregation is possible in the case of monetary matrices, the method has

\footnotetext{
${ }^{3}$ Based on another study by Carter (1980), Feldman, McClain and Palmer (1987) proposed a method for comparing matrices with incomplete data. The study in question describes an adapted version of the original ideas for square matrices, taking account of the direct and indirect effects on the matrices.

${ }^{4}$ The first case would evaluate technical change, whereas the second would estimate the technological differences between two economies with different technologies.
}

shortcomings, because it supports evaluation of cost trends only, which could stem from technical changes or shifts in input prices, or both. ${ }^{5}$

Structural decomposition has also been widely used in evaluating technical changes. ${ }^{6}$ This method consists of breaking down the sources of the variation in gross production value. Based on the production equation, $X=B Y$, the total variation in gross production $\Delta X$ can be split into three parts, as shown in the following equation:

$$
\Delta X=B \Delta Y+Y \Delta B+\Delta B \Delta Y
$$

According to that expression, differences in the value of production owing to changes in final demand can be estimated by setting the matrix of technical coefficients: $\Delta X=B \Delta Y$. Differences in output value resulting from changes in technical coefficients are obtained by setting the vector of final demand: $\Delta X=Y \Delta B$. With this method, technical change is estimated by the difference in the technical coefficients between the two matrices which, to obtain the same net output, use different amounts of intermediate inputs. The greater the quantity, or value, of those inputs, the lower productivity will be. It is also possible to identify the sectors of the economy which, in the aggregate, record the largest changes between two points in time, ${ }^{7}$ and, in turn, the coefficients responsible for the change.

\footnotetext{
5 That aggregation reveals the production cost of products or sectors.

${ }^{6}$ On this point, see Lahr and Dietzenbacher (2001).

${ }^{7}$ This is possible only when the matrix is expressed in monetary values.
} 
Structural decomposition can also be used to identify (approximately) the differences between two matrices in time and space. To specifically measure the impact of the technical changes, the vector of final demand of the economy must be set between two periods, allowing only the technical coefficients matrix to vary. Carter (1967) pioneered a study that analysed the technological changes that have taken place in the United States economy, comparing the matrices of 1947 and 1958. Given the vector of final demand for 1962 and the coefficients of the inverse matrices of 1947 and 1958, the author obtained the gross production vector for the sectors of the United States economy compatible with that demand and each period's Leontief matrices. The difference between the two gross production vectors determines the variation in production needed to satisfy the same final demand vector in the two periods. A positive variation would imply a productivity loss, because the same demand would require a larger amount of expenditure to produce the goods or services of the sector in question. In contrast, a negative variation would mean a reduction in expenditure and a consequent increase in productivity. All of the sectors of the economy can be aggregated to determine which of the two matrices is more productive.

Although this method allows for direct comparisons to be made between sectors of two technological matrices, comparing two economies poses a number of problems. This is because the aggregation depends on the composition of the gross production vector which, in turn, depends on the composition of final demand, a variable that is exogenous to the system. Differences in the composition of demand can produce different results. Whereas the share of low-productivity sectors in the economy as a whole tends to decline, the share of high-productivity sectors tends to increase. As a result, attributing the same share to the productive sectors of the two matrices could lead to distortions in the analysis. Carter (1967), for example, imposed the 1962 composition of final demand on the years 1947 and $1958 .{ }^{8}$

Feldman, McClain and Palmer (1987) proposed a "rowscaler" methodology. To explain it, the authors start with two different technological matrices (each one associated with a point in time), and a single vector of final demand. The values of gross output needed to obtain the final demand vector are given by:

$$
X^{t}=A^{t} X^{t}+Y=\left(I-A^{t}\right)^{-1} Y=B^{t} Y, \quad t=1,2
$$

8 If Carter (1967) had used a final demand vector with different composition, the result would probably have been different.
The diagonalization of the production vectors obtained in each period generates the diagonal matrices $\hat{X}^{t}$, which have the values of the production vectors in the leading diagonal, and zeros in the other cells. Multiplying the diagonalized production vector obtained in the first period by that obtained in the second — both based on the same demand but with different technologies — gives expression (3):

$$
\Gamma=\hat{X}^{2}\left[\hat{X}^{1}\right]^{-1}
$$

where $\Gamma$ Is the matrix ${ }^{9}$ formed by the $\gamma_{i j}$ elements. If $\gamma_{i i}^{2}>1$, sector $i$ of matrix 2 is less productive than the same sector of matrix 1 ; if $\gamma_{i i}^{2}<1$, sector $i$ of matrix 2 is more productive than the corresponding sector of matrix 1. Lastly, if $\gamma_{i i}^{2}=1$, the two matrices can be said to have the same productivity. In the specific case where the final demand vector is unitary, it is possible to directly compare the direct and indirect coefficients of the inverse Leontief matrix for the two countries. The sum of each of the rows of the Leontief matrix would indicate the direct and indirect quantity of goods and services needed to obtain one unit of good $i$ to satisfy final demand. ${ }^{10}$

The foregoing method takes account of the production of all goods needed to satisfy a unitary demand vector, whose elements contain one unit of demand for each good and service in the economy, in other words a vector with unit values in each row. When the aim is to investigate the quantity of goods needed to satisfy the demand for one unit of a given good $i$, the method consists of summing the rows of the Leontief matrix corresponding to that good. That process aggregates the direct and indirect quantities of goods and services needed to produce one unit of the good or service being analysed.

In addition to the three methods described above, input-output analysis also developed a specific methodology to evaluate the trend of TFP, in the tradition

\footnotetext{
${ }^{9}$ In that matrix, the elements outside the leading diagonal are zero by construction.

10 This procedure makes it possible to compare the same sectors of different matrices to ascertain whether a specific sector is more or less productive than the equivalent sector in the other economy. It is impossible to determine whether one economy is more or less productive than the other. Only the extreme case where all sectors of one of the matrices are more productive than the respective sectors of the other matrix, would it be possible to state, unequivocally, that one of the matrices is more productive than the other. To compare aggregate production, it would be necessary to set a vector of final demand or production, as proposed by Carter (1967).
} 
of economic growth theories. ${ }^{11}$ Nonetheless, the analysis cannot be applied to the international input-output matrix database, because this does not contain information on factor endowments (capital, labour and land) for all the economies. To determine the trend of TFP in the manufacturing sectors of the two countries, the following subsection uses another theoretical approach based on statistical methods.

\section{Databases and methodology}

The databases used in the analysis are the WIOD (2012) global input-output tables. The tables were constructed as a result of a huge task to make national input-output tables compatible with one another, undertaken by a group of research institutes around the world, coordinated by the University of Groningen. ${ }^{12}$ The project, financed by the European Commission and published on the Internet in April 2012, will make a major contribution to deepening understanding of the world economy. ${ }^{13}$

The WIOD has data on national input-output tables for the years between 1995 and 2009, together with estimations of global input-output tables that show international flows of goods and services. The data cover a total of 40 countries, and estimations for the "rest of the world" - the regional grouping created to reconcile national foreign trade flows- - In addition to the national and international matrices, numerous other variables are provided per country, such as factor endowments, price indices, and the functional distribution of income.

This article uses the global input-output tables for 1995-2009 to calculate the productivity vector. These matrices abide by the original Leontief formulation, $X=(I-A)^{-1} Y$, where:

$X=\left[\begin{array}{c}X^{1} \\ \cdots \\ X^{2} \\ \cdots \\ \vdots \\ \cdots \\ X^{k}\end{array}\right], Y=\left[\begin{array}{c}Y^{1} \\ \cdots \\ Y^{2} \\ \cdots \\ \vdots \\ \cdots \\ Y^{k}\end{array}\right]$ and $A=\left[\begin{array}{ccccccc}A^{11} & \vdots & A^{12} & \vdots & \cdots & \vdots & A^{1 k} \\ \cdots & \cdots & \cdots & \cdots & \cdots & \cdots & \cdots \\ A^{21} & \vdots & A^{22} & \vdots & \cdots & \vdots & A^{2 k} \\ \cdots & \cdots & \cdots & \cdots & \cdots & \cdots & \cdots \\ \vdots & \vdots & \vdots & \vdots & \ddots & \vdots & \vdots \\ \cdots & \cdots & \cdots & \cdots & \cdots & \cdots & \cdots \\ A^{k 1} & \vdots & A^{k 2} & \vdots & \cdots & \vdots & A^{k k}\end{array}\right]$ (4)

\footnotetext{
11 On this topic, see Miller and Blair (2009).

12 The editor in charge is Marcel Timmer of the University of Groningen.

13 [Online] www.wiod.org/database.
}

In expression (4), $X^{1}, X^{2}, \ldots, X^{\mathrm{k}}$ are ( $\left.35 \mathrm{x} 1\right)$ vectors of national production, each of which contains the output values of the 35 sectors of economic activity covered by the matrix. The vector $Y$ denotes final demand and has the same interpretation. The matrix is formed by 1,681 matrices of technical coefficients (of dimension $35 \times 35$ ) which identify the origin (country and sector) and destination (country and sector) of intermediate consumption. ${ }^{14}$ Matrix $A$ is calculated by dividing the intermediate consumption matrix, of the same dimension as matrix $A$, by vector $X$.

Those data are used to obtain the global Leontief matrix for the years 1995 and 2009, which serves as a basis for calculating the production needed to satisfy one unit of final demand for a given good or service in a specific country. Expression 5 contains the definitions of that matrix, in which $N$ and $M$ indicate the countries, and $B^{N M}$ the sub-matrix of technical coefficients of those two countries. In this system, when $N$ is equal to $M$, the matrix $B^{N M}$ designates the domestic coefficients of economy $\mathrm{N}$, in other words the quantities of goods produced in economy $N$ that are needed to produce one unit of the good in that economy. When $N$ is different from $M$, the matrix $B^{N M}$ denotes the external coefficients of economy $N$ : the quantities of goods and services produced in the rest of the world that are needed to produce one unit of the good in economy $N$.

$$
B=\left[\begin{array}{ccccccc}
B^{11} & \vdots & B^{12} & \vdots & \ldots & \vdots & B^{1 k} \\
\ldots & \ldots & \ldots & \ldots & \ldots & \ldots & \ldots \\
B^{21} & \vdots & B^{22} & \vdots & \ldots & \vdots & B^{2 k} \\
\ldots & \ldots & \ldots & \ldots & \ldots & \ldots & \ldots \\
\vdots & \vdots & \vdots & \vdots & \ddots & \vdots & \vdots \\
\ldots & \ldots & \ldots & \ldots & \ldots & \ldots & \ldots \\
B^{k 1} & \vdots & B^{k 2} & \vdots & \ldots & \vdots & B^{k k}
\end{array}\right]
$$

and

$$
B^{N M}=\left[\begin{array}{cccc}
b_{11} & b_{12} & \cdots & b_{1 j} \\
b_{21} & b_{22} & \cdots & b_{2 j} \\
\vdots & \vdots & \ddots & \vdots \\
b_{i 1} & b_{i 2} & \cdots & b_{i j}
\end{array}\right]^{N M}
$$

As noted above, the production needed to satisfy one unit of demand for a good in a given country is calculated by adding the values of the columns of the Leontief matrix. This can be done directly with respect

14 The number of $A^{\mathrm{kk}}$ matrices stems from the number of regions in the database (41). 
to all economic sectors and countries of interest. ${ }^{15}$ The resulting sum can be broken down into two elements representing domestic and external requirements. The domestic requirements are calculated as the sum of the $b_{i j}$ values in the $B^{N N}$ matrix, and the external requirements are calculated as the sum of bij values of the $B^{N M}$ matrices, $N \neq M$. The ratio between the quantities needed in the two countries generates the matrix $\Gamma$, whose meaning and interpretation are identical to those presented in subsection 2 of section II. In the following analysis, two other matrices are calculated with those characteristics: $\Gamma^{\mathrm{d}}$, which indicates the quantities of domestically produced goods and services that are needed to produce $\mathrm{i}$ goods in the two economies; and $\Gamma^{\mathrm{e}}$, calculated as the ratio between the quantities of imported goods and services used in the production of $i$ goods in the two economies.

This article only presents the values for the Brazilian and Mexican economies in the 14 activity sectors of manufacturing industry mentioned in its introduction. The values of the global input-output tables are expressed in millions of dollars at current prices each year. As the productivity indicators are expressed as monetary units of production of the goods, the inter-temporal comparisons contain variations in both quantities and relative prices, which restrict analysis possibilities. It should be remembered that the analyses do not consider differences in the purchasing power of currencies. In 2009, one dollar in Brazil was equivalent in purchasing power to US\$ 1.32 at United States prices, whereas in Mexico, one dollar was worth US\$ 2.19 in purchasing-power terms. That meant that a dollar of demand for a given good in Brazil was equivalent to a different amount of that good in Mexico. Nonetheless, relative production studies do not need adjustments for purchasing power parity, since they express relations between production values at a given place and time.

\section{Results}

Although Brazil's economy is much larger than Mexico's, their manufacturing industries display very similar structures. In 2009, the gross value of industrial output amounted to US\$ 940,559 million in Brazil and US\$ 470,853 million in Mexico (see table 1). In the Brazilian economy, $73 \%$ of gross production value was accounted for by five industries: food, beverages and tobacco; coke and refined petroleum; chemicals;

15 This is equivalent to calculating the value of $X$ needed to satisfy a unit vector $Y$. metallurgy and metal products; electrical and optical equipment; and transport equipment. The equivalent share was even greater in the case of Mexico, at $80.5 \%$. The structural change coefficient, which had a value of 0.89 in 2009 , illustrates the similarity between the two industrial structures and between the two economies more clearly. ${ }^{16}$

It is also worth highlighting the importance of the food, beverages and tobacco industry in the two countries' industrial structure. This sector accounted for $19.8 \%$ of Brazil's gross industrial production value in 2009, and $24.6 \%$ in the case of Mexico. The greatest difference between the structures of the two countries corresponds to the electrical and optical equipment sector, which represented almost 15\% of Mexican industry in 2009 compared to $6.6 \%$ in the case of Brazil.

Table 2 reports productivity indicators for 1995 , in terms of the quantities of goods (domestic and imported) needed to produce one monetary unit of the goods of each industry in each country. The last three columns show the ratios between those amounts in the two countries. Taking the data for Brazil as an example, in 1995 the food, beverages and tobacco industry required US\$2.27 for each dollar of output, representing US\$ 0.12 in imported goods and services plus US\$ 2.14 of goods and services produced domestically. In Mexico, to produce one dollar of food, beverages and tobacco required US\$ 2.22 of production in all sectors of the economy -US\$ 0.32 of imported goods and services, and US\$ 1.90 of domestic production.

The ratio between the two coefficients of production in the food, beverages and tobacco sector was 1.02 in 1995, which shows that the Brazilian industry was slightly less productive than its Mexican counterpart. Table 2 also reports the values of the leading diagonal of the $\Gamma^{d}$ matrix, which relates the quantities of domestically produced goods and services that are needed for the production of food and beverages in the two economies. In the case of the food, beverages and tobacco industry, the ratio was 1.13. This means that the Brazilian food and beverages industry required more monetary units of domestic production than its Mexican equivalent, and that the productive chain in Mexico also required more imports. ${ }^{17}$

\footnotetext{
${ }^{16}$ Coefficient of correlation between the distribution (percentage) of gross production value between the two economies.

17 Those calculations do not include imports of manufactured food and beverages by the two countries, but only the imports of raw materials (goods and services) needed to produce one monetary unit of the goods in question.
} 
TABLE 1

Brazil and Mexico: gross industrial production value, 2009 (US\$ million)

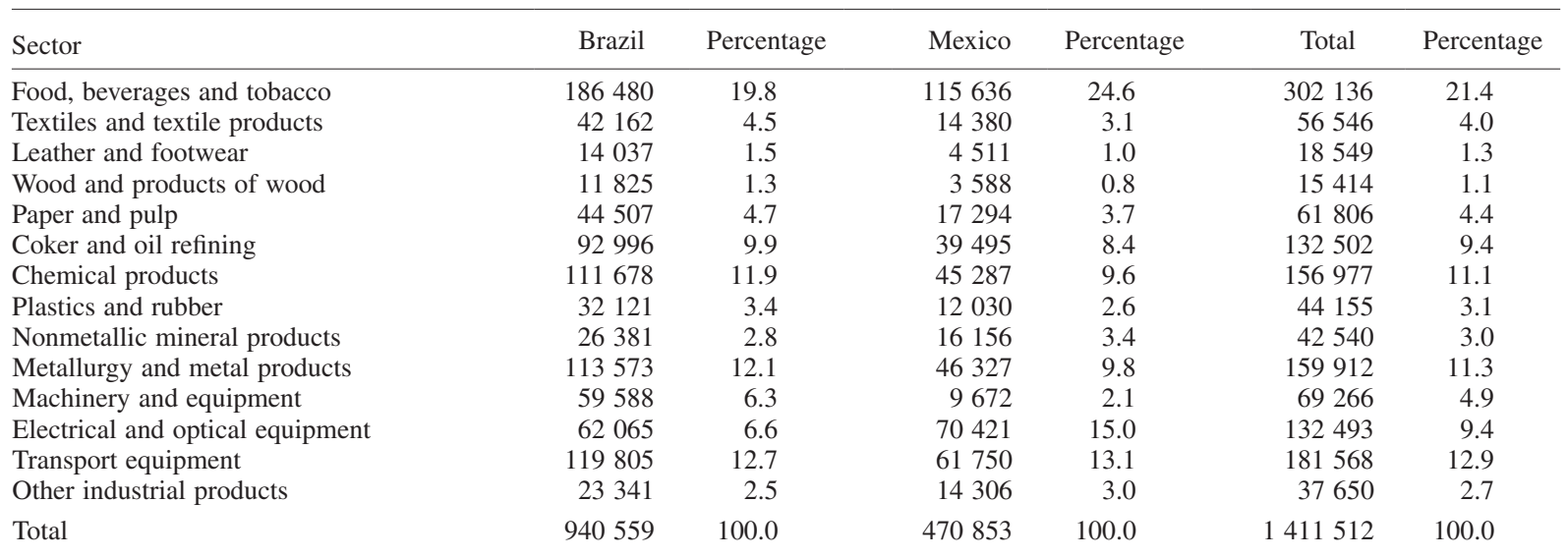

Source: prepared by the authors, on the basis of information from the World Input-Output Database (wIOD).

The data of table 2 show that, in 1995, 10 segments of Brazilian industry were more productive than their counterparts in Mexico, namely: textiles and textile products; wood and products of wood; paper and pulp; chemical products; plastics and rubber; metallurgy and metallic products; machinery and equipment; electrical and optical equipment; transport equipment; and other industrial products. Only in the leather and footwear, non-metallic mineral products, and coke and refined petroleum sectors did the productivity of Mexican industry greatly exceed that of Brazil. In the specific case of coke and refined petroleum, the productivity difference was largely due to the greater need for imports in Brazilian industry, which was not yet self-sufficient in oil production.

The data of figure 3 show a very different situation in 2009, because Mexico's industry had overtaken Brazil's in productivity terms. All industrial segments,

TABLE 2

Brazil and Mexico: input requirements and relative productivity, 1995

\begin{tabular}{|c|c|c|c|c|c|c|c|c|c|}
\hline \multirow{3}{*}{ Industrial sectors } & \multicolumn{6}{|c|}{ Production needed } & \multirow{2}{*}{\multicolumn{3}{|c|}{$\Gamma$}} \\
\hline & \multicolumn{3}{|c|}{ Brazil } & \multicolumn{3}{|c|}{ Mexico } & & & \\
\hline & Total & Domestic & External & Total & Domestic & External & Total & Domestic & External \\
\hline Food, beverages and tobacco & 2.2676 & 2.1436 & 0.1241 & 2.2244 & 1.8975 & 0.3269 & 1.0194 & 1.1297 & 0.3795 \\
\hline Textiles and textile products & 1.9997 & 1.8188 & 0.1809 & 2.3634 & 1.8648 & 0.4987 & 0.8461 & 0.9753 & 0.3628 \\
\hline Leather and footwear & 2.4597 & 2.2514 & 0.2084 & 2.3231 & 1.9371 & 0.3860 & 1.0588 & 1.1622 & 0.5398 \\
\hline Wood and products of wood & 1.8489 & 1.7591 & 0.0898 & 2.1605 & 1.8841 & 0.2764 & 0.8558 & 0.9337 & 0.3249 \\
\hline Paper and pulp & 2.0535 & 1.8796 & 0.1739 & 2.0616 & 1.6402 & 0.4214 & 0.9961 & 1.1459 & 0.4127 \\
\hline Coker and oil refining & 2.5341 & 2.1945 & 0.3397 & 2.1276 & 1.9858 & 0.1418 & 1.1911 & 1.1051 & 2.3953 \\
\hline Chemical products & 2.1038 & 1.8931 & 0.2107 & 2.1552 & 1.8632 & 0.2920 & 0.9762 & 1.0161 & 0.7215 \\
\hline Plastics and rubber & 2.2005 & 1.9492 & 0.2513 & 2.3242 & 1.7562 & 0.5679 & 0.9468 & 1.1099 & 0.4425 \\
\hline Nonmetallic mineral products & 1.9870 & 1.8371 & 0.1499 & 1.8275 & 1.5988 & 0.2287 & 1.0872 & 1.1490 & 0.6554 \\
\hline Metallurgy and metal products & 2.1255 & 1.9193 & 0.2062 & 2.3187 & 1.7878 & 0.5309 & 0.9167 & 1.0736 & 0.3884 \\
\hline Machinery and equipment & 2.1956 & 1.9914 & 0.2043 & 2.2692 & 1.5589 & 0.7104 & 0.9676 & 1.2775 & 0.2875 \\
\hline Transport equipment & 2.4428 & 2.1795 & 0.2633 & 2.4756 & 1.6337 & 0.8419 & 0.9867 & 1.3341 & 0.3127 \\
\hline Other industrial products & 1.9878 & 1.8411 & 0.1467 & 2.3174 & 1.6576 & 0.6598 & 0.8578 & 1.1107 & 0.2224 \\
\hline
\end{tabular}

Source: prepared by the authors, on the basis of information from the World Input-Output Database (WIOD). 
apart from the textile products, electrical and optical equipment, and other industrial products industries were less productive in Brazil than in Mexico. Those three sectors were already more productive in Brazil in 1995, and the advantages with respect to Mexico had diminished in two of them by 2009. In contrast, the four sectors of Mexican industry that were more productive in 1995 had actually increased their advantage by 2009 .

In this situation, it is natural to ask how a team that won a match 10-4 can lose a second one 3-11? Table 4 , which reports the rates of change of the indicators shown in the previous tables between 1995 and 2009, answers that question. Comparing the data for the two reference years, there are significant changes in the goods and services requirements in the two countries; and Brazilian industry recorded greater increases in all sectors, except electrical equipment.

In Brazil, requirements increased in all industrial sectors, except for the leather and footwear industry. This indicates a loss of productivity, which could represent both a physical decline and an adverse trend in relative prices. In the Mexican case, there were considerable productivity gains in eight of the 14 manufacturing industries between 1995 and 2009. The productivity loss in the other sectors was less than in Brazilian industry, except in the case of electrical equipment. Another important characteristic of Mexican industry is that the growth in imported goods and service requirements was offset by a reduction in requirements for domestic goods and services. Thus, compared to the Brazilian case, the productivity of Mexican industry evolved by replacing domestic raw materials with imports, in other words, that trade liberalization generated larger productivity gains in Mexico than in Brazil. ${ }^{18}$

18 The only exception to that rule was the coke and refined petroleum industry.

TABLE 3

Brazil and Mexico: input requirements and relative productivity, 2009

\begin{tabular}{|c|c|c|c|c|c|c|c|c|c|}
\hline \multirow{3}{*}{ Industrial sectors } & \multicolumn{6}{|c|}{ Production needed } & \multirow{2}{*}{\multicolumn{3}{|c|}{$\Gamma$}} \\
\hline & \multicolumn{3}{|c|}{ Brazil } & \multicolumn{3}{|c|}{ Mexico } & & & \\
\hline & Total & Domestic & External & Total & Domestic & External & Total & Domestic & External \\
\hline Food, beverages and tobacco & 2.5257 & 2.3525 & 0.1732 & 2.1461 & 1.7900 & 0.3560 & 1.1769 & 1.3142 & 0.4864 \\
\hline Textiles and textile products & 2.1539 & 1.9064 & 0.2475 & 2.2520 & 1.6807 & 0.5713 & 0.9564 & 1.1343 & 0.4332 \\
\hline Leather and footwear & 2.3820 & 2.1767 & 0.2054 & 2.1947 & 1.7799 & 0.4148 & 1.0854 & 1.2229 & 0.4952 \\
\hline Wood and products of wood & 2.1030 & 1.9517 & 0.1514 & 2.0346 & 1.7229 & 0.3117 & 1.0336 & 1.1328 & 0.4855 \\
\hline Paper and pulp & 2.1271 & 1.9196 & 0.2075 & 2.0509 & 1.6050 & 0.4460 & 1.0371 & 1.1960 & 0.4653 \\
\hline Coker and oil refining & 2.7676 & 2.3908 & 0.3768 & 2.2069 & 1.9969 & 0.2100 & 1.2541 & 1.1973 & 1.7941 \\
\hline Chemical products & 2.5001 & 2.1684 & 0.3317 & 2.1988 & 1.7836 & 0.4152 & 1.1370 & 1.2157 & 0.7990 \\
\hline Plastics and rubber & 2.4443 & 2.0914 & 0.3530 & 2.3837 & 1.6912 & 0.6925 & 1.0254 & 1.2366 & 0.5097 \\
\hline Nonmetallic mineral products & 2.2249 & 2.0207 & 0.2042 & 1.8193 & 1.5656 & 0.2537 & 1.2230 & 1.2907 & 0.8049 \\
\hline Metallurgy and metal products & 2.3269 & 2.0570 & 0.2700 & 2.2955 & 1.6944 & 0.6012 & 1.0137 & 1.2140 & 0.4491 \\
\hline Machinery and equipment & 2.4189 & 2.1234 & 0.2955 & 2.3393 & 1.5334 & 0.8059 & 1.0341 & 1.3848 & 0.3667 \\
\hline Electrical and optical equipment & 2.5327 & 2.0422 & 0.4905 & 3.0350 & 1.4594 & 1.5756 & 0.8345 & 1.3993 & 0.3113 \\
\hline Transport equipment & 2.7291 & 2.3044 & 0.4246 & 2.4459 & 1.5720 & 0.8739 & 1.1158 & 1.4659 & 0.4859 \\
\hline Other industrial products & 2.1408 & 1.9348 & 0.2060 & 2.3324 & 1.5828 & 0.7496 & 0.9178 & 1.2224 & 0.2748 \\
\hline
\end{tabular}

Source: prepared by the authors, on the basis of information from the World Input-Output Database (WIOD). 
TABLE 4

Brazil and Mexico: variation in input requirements and relative productivity, from 1995 to 2009

(Percentages)

\begin{tabular}{|c|c|c|c|c|c|c|c|c|c|}
\hline \multirow[b]{2}{*}{ Industrial sectors } & \multicolumn{6}{|c|}{ Production needed } & \multirow{2}{*}{ Total } & \multirow{2}{*}{ Domestic } & \multirow{2}{*}{ External } \\
\hline & \multicolumn{3}{|c|}{ Brasil } & \multicolumn{3}{|c|}{ México } & & & \\
\hline Food, beverages and tobacco & 11.4 & 9.7 & 39.6 & -3.5 & -5.7 & 8.9 & 15.4 & 16.3 & 28.2 \\
\hline Textiles and textile products & 7.7 & 4.8 & 36.8 & -4.7 & -9.9 & 14.6 & 13.0 & 16.3 & 19.4 \\
\hline Leather and footwear & -3.2 & -3.3 & -1.4 & -5.5 & -8.1 & 7.5 & 2.5 & 5.2 & -8.3 \\
\hline Wood and products of wood & 13.7 & 10.9 & 68.5 & -5.8 & -8.6 & 12.8 & 20.8 & 21.3 & 49.4 \\
\hline Paper and pulp & 3.6 & 2.1 & 19.3 & -0.5 & -2.1 & 5.8 & 4.1 & 4.4 & 12.7 \\
\hline Coker and oil refining & 9.2 & 8.9 & 10.9 & 3.7 & 0.6 & 48.1 & 5.3 & 8.3 & -25.1 \\
\hline Chemical products & 18.8 & 14.5 & 57.5 & 2.0 & -4.3 & 42.2 & 16.5 & 19.7 & 10.7 \\
\hline Plastics and rubber & 11.1 & 7.3 & 40.4 & 2.6 & -3.7 & 21.9 & 8.3 & 11.4 & 15.2 \\
\hline Nonmetallic mineral products & 12.0 & 10.0 & 36.2 & -0.5 & -2.1 & 10.9 & 12.5 & 12.3 & 22.8 \\
\hline Metallurgy and metal products & 9.5 & 7.2 & 30.9 & -1.0 & -5.2 & 13.2 & 10.6 & 13.1 & 15.6 \\
\hline Machinery and equipment & 10.2 & 6.6 & 44.7 & 3.1 & -1.6 & 13.4 & 6.9 & 8.4 & 27.5 \\
\hline Transport equipment & 11.7 & 5.7 & 61.3 & -1.2 & -3.8 & 3.8 & 13.1 & 9.9 & 55.4 \\
\hline Other industrial products & 7.7 & 5.1 & 40.4 & 0.6 & -4.5 & 13.6 & 7.0 & 10.1 & 23.5 \\
\hline
\end{tabular}

Source: prepared by the authors, on the basis of information from the World Input-Output Database (WIOD).

\section{III}

\section{Factor productivity}

As it is impossible to apply input-output matrix analysis owing to the lack of data on factor endowments (capital, labour and land) in the set of countries forming the area referred to as "rest of the world" in the WIOD, factor productivity in the 14 industrial sectors of Brazil and Mexico was evaluated using a different approach.

In this case, TFP was calculated on the basis of the "Solow residual" (Solow, 1957). To improve the analysis of productivity trends, separating the effects of demand and supply crises on that indicator from longer-term trends (such as technological progress and economies of scale), a complementary statistical approach was used. This firstly involves fitting a production function and then using the estimated coefficients to calculate productivity by means of a decomposition. Under this approach, the productivity trend is the portion of GDP growth that is explained neither by factor accumulation
- a concept present in the Solow (1957) approach- nor by specific random phenomena. ${ }^{19}$

\section{Production frontier and decomposition of productivity}

This study adopted the stochastic-frontier econometric approach to fit the production function. This approach

\footnotetext{
19 It is not necessary to estimate a production function to calculate TFP. The calculation can be based on statistics of the trend of GDP, factor endowments and the factor shares in the functional distribution of income. Nonetheless, a strictly accounting approach accentuates the effects of supply and demand crises in the measurement of productivity trends. Econometric approaches, on the other hand, make it possible to remove random phenomena from the variations in GDP and factor endowments, and, depending on the technique, measurement errors. In general, those approaches produce more stable TFP estimations with more plausible economic interpretations.
} 
has been, widely applied in microeconomic studies and was used with satisfactory results in recent studies for the international comparisons of factor productivity at more aggregate levels. On this point, see Kneller and Stevens (2003); Kumbhakar and Wang (2005); Garcia, Souza and Pires (2008), and Pires and Garcia (2012).

The first advantage of the approach is that the productivity difference between two economies is not restricted to technological differences. The stochastic production frontier admits the possibility of inefficiency in production and, therefore, that there may be productivity differences between two economies that operate at the same technological level. Another advantage is that, when panel data are used, the stochastic frontier produces better estimates then ordinary least squares (oLs) in the absence of heterogeneity controls. ${ }^{20}$ This is because it is based on an error component model that makes it possible to separate random phenomena from those that can be attributed to omitted factors, such as the output gap caused by labour unemployment.

Expression (6) defines the stochastic production frontier as a production function fitted through a theoretical measure of technical inefficiency.

$$
\begin{gathered}
Y_{i t}=F\left(B_{t}, K_{i t}, H_{i t}, L_{i t}\right) \cdot \exp \left(-u_{i}\right), \\
i=1,2, \ldots, N \text { and } t=1, \ldots, T
\end{gathered}
$$

This expression uses the following definitions:

- $\quad Y_{i t}$ is industrial value added in country $i$ at time $t$;

- $\quad F$ is the production function;

- $\quad K_{i t}, H_{i t}$ and $L_{i t}$ are the quantities of capital, skilled labour and unskilled labour used by the industry of country $i$ at time $t$;

- $\quad B_{t}$ is the level of productivity reflecting optimal practice at time $t$, and

- $u_{i t} \geq 0$ is the measure of technical inefficiency of the industry of country $i$ at a time $t$.

Based on the stochastic production frontier, the Bauer-Kumbhakar decomposition of the trend of TFP is performed (see Kumbhakar, Denny and Fuss, 2000), to identify four sources of productivity variation: technical progress, variation in technical inefficiency, variation

\footnotetext{
${ }^{20}$ As shown in Garcia, Souza and Pires (2008), aggregate production functions which control the heterogeneity produce estimations without economic meaning; for example, the African economies would show the highest rate of technological progress while the industrial economies would display regression or stagnation. This happens because there is a very close linear link between capital, technology and the quantity of labour used, because the technologies are embedded in the capital.
}

of allocative inefficiency, and economies of scale. The decomposition also makes it possible to interpret the trend of TFP more precisely and to identify different patterns. For example, although two economies may display the same TFP growth rate, in one case the increase may stem from technological progress and in the other from economies of scale, which are very different economic processes.

In mathematical terms, the decomposition of the productivity trend under the production-frontier model is obtained by differentiating that frontier with respect to time. Following numerous algebraic manipulations, the time differential of the production frontier gives equation (7), which expresses the rate of growth of industrial value added in a given country $i$ at a time $t$, as the sum, weighted by the respective elasticities $(\varepsilon)$, of the rates of: (i) variation in optimal practice, also known as the rate of technological progress; (ii) factor accumulation (capital, skilled and unskilled labour), and (iii) variation in technical inefficiency.

$$
\frac{\dot{Y}_{i t}}{Y_{i t}}=\varepsilon_{B} \cdot \frac{\dot{B}_{i t}}{B_{i t}}+\varepsilon_{K} \cdot \frac{\dot{K}_{i t}}{K_{i t}}+\varepsilon_{H} \cdot \frac{\dot{H}_{i t}}{H_{i t}}+\varepsilon_{L} \cdot \frac{\dot{L}_{i t}}{L_{i t}}-\dot{u}_{i t}
$$

Assuming Hicks-neutral technology which means that $\varepsilon_{B}=1$, and using the TFP definition established by equation (8) - the Solow residual— in which $S_{j}$ is the share of productive factor $j$ in the functional distribution of income, it is possible to find a new decomposition for the variation of TFP.

$$
\frac{\dot{A}_{i t}}{A_{i t}}=\frac{\dot{Y}_{i t}}{Y_{i t}}-S_{K} \cdot \frac{\dot{K}_{i t}}{K_{i t}}-S_{H} \cdot \frac{\dot{H}_{i t}}{H_{i t}}-S_{L} \cdot \frac{\dot{L}_{i t}}{L_{i t}}
$$

Combining (7) and (8), gives:

$$
\begin{aligned}
\frac{\dot{A}_{i t}}{A_{i t}}=\frac{\dot{B}_{i t}}{B_{i t}} & +\left(\varepsilon_{K}-S_{K}\right) \cdot \frac{\dot{K}_{i t}}{K_{i t}}+\left(\varepsilon_{L}-S_{L}\right) \cdot \frac{\dot{L}_{i t}}{L_{i t}} \\
& +\left(\varepsilon_{H}-S_{H}\right) \cdot \frac{\dot{H}_{i t}}{H_{i t}}-\dot{u}_{i t}
\end{aligned}
$$

A transformation can be applied to simplify the foregoing expression (9) and isolate the components of the rate of change of TFP. Defining:

$$
R T S=\sum_{j} \varepsilon_{j} \text { and } \lambda_{j}=\frac{\varepsilon_{j}}{R T S}, j=K, H, L
$$


in which RTS denotes returns to scale, gives equation (10):

$$
\begin{aligned}
& \frac{\dot{A}_{i t}}{A_{i t}}=\frac{\dot{B}_{i t}}{B_{i t}}-\dot{u}_{i t}+(R T S-1) \cdot\left[\lambda_{K} \cdot \frac{\dot{K}_{i t}}{K_{i t}}+\lambda_{H} \cdot \frac{\dot{H}_{i t}}{H_{i t}}+\lambda_{L} \cdot \frac{\dot{L}_{i t}}{L_{i t}}\right] \\
& +\left[\left(\lambda_{K}-S_{K}\right) \cdot \frac{\dot{K}_{i t}}{K_{i t}}+\left(\lambda_{H}-S_{H}\right) \cdot \frac{\dot{H}_{i t}}{H_{i t}}+\left(\lambda_{L}-S_{L}\right) \cdot \frac{\dot{L}_{i t}}{L_{i t}}\right]
\end{aligned}
$$

which states that the rate of change of TFP can be broken down into four components:

(i) technical progress measured by $\dot{B}_{i t} / B_{i t}$;

(ii) change in technical efficiency approximated by $-\dot{u}_{i t}$

(iii) change in productivity owing to the effect of a change in the scale of production, calculated by

$$
(R T S-1) \cdot\left[\lambda_{K} \cdot \frac{\dot{K}_{i t}}{K_{i t}}+\lambda_{H} \cdot \frac{\dot{H}_{i t}}{H_{i t}}+\lambda_{L} \cdot \frac{\dot{L}_{i t}}{L_{i t}}\right],
$$

(iv) change in allocative efficiency, measured by

$$
\left[\left(\lambda_{K}-S_{K}\right) \cdot \frac{\dot{K}_{i t}}{K_{i t}}+\left(\lambda_{H}-S_{H}\right) \cdot \frac{\dot{H}_{i t}}{H_{i t}}+\left(\lambda_{L}-S_{L}\right) \cdot \frac{\dot{L}_{i t}}{L_{i t}}\right]
$$

Under constant returns to scale, $R T S=1$, so the third component of the productivity change is cancelled out; but if RTS differs from 1, part of the variation in productivity is explained by the change in the scale of production. Moreover, if the ratios between the elasticities and $R T S\left(\lambda_{j}\right)$ are equivalent to the respective factor shares in the functional distribution of income $\left(S_{j}\right)$, then the industry is efficient in terms of factor allocation. In that case, by definition, there are no productivity changes attributed to changes in the allocation of factors. Lastly, in this model, technical progress accounts for at least as much of the variation in productivity. Only when there are no technical or allocative inefficiencies, or increasing or decreasing returns to scale, is the measure of the variation of productivity, $\dot{A} / A$, identical to technical progress, $\dot{B} / B$. This approach thus covers a larger number of possible situations, without very arbitrary restrictions on the shape of the production function and its properties.

\section{Databases and econometric model}

The data used in the analysis also come from the WIOD and relate to the 14 manufacturing industries analysed above. For each industrial sector, a stochastic frontier is estimated based on the data from 40 countries with regard to value added $\left(Y_{i t}\right)$, capital endowment $\left(K_{i t}\right)$, hours of skilled labour employed $\left(H_{i t}\right)$ and hours of unskilled labour employed $\left(L_{i t}\right)$ between 1995 and 2009. Hours of skilled labour employed are equivalent to the sum of the number of hours worked by medium- and high-skilled workers. The monetary values are expressed in constant 1995 dollars. ${ }^{21}$ As the analyses were conducted at the industrial-sector level, the data were not adjusted for purchasing power parity, as is more frequent in aggregate macroeconomic analyses.

The econometric model estimated is a translog function of the value added of the three factors of production and time $(t)$, which captures the trend of the frontier. The function in question, described in equation (11), has 14 explanatory variables: the levels of factors of production and time $\left(K_{i t}, H_{i t}, L_{i t}\right.$ and $\left.t\right)$, the squares of the factors of production and time $\left(K_{i t}^{2}, H_{i t}^{2}, L_{i t}^{2}\right.$ and $\left.t^{2}\right)$ and the interactions between them $\left(K_{i t} \cdot H_{i t}, K_{i t} \cdot L_{i t}, K_{i t} . t, H_{i t} . L_{i t}\right.$, $H_{i t} . t$ and $\left.L_{i t} . t\right)$. The variables $u_{i t}$ and $v_{i t}$ are the model's error components: the first of these measures technical inefficiency and has a distribution $u_{i t} \sim$ i.i.d $N^{+}\left(\mu, \sigma_{u}^{2}\right)$; and the second is the random error with distribution $v_{i t} \sim$ i.i.d $N\left(0, \sigma_{v}^{2}\right)$. The values of all variables (except time) are expressed in natural logarithms and are deviations from the mean of each series (including time), such that the estimated coefficients of each regression are fitted to the sample mean.

$$
\begin{aligned}
& \ln y_{i t}= \\
& \beta_{0}+\beta_{t} \cdot t+\beta_{K} \ln K_{i t}+\beta_{L} \ln L_{i t}+\beta_{H} \ln H_{i t} \\
& +1 / 2 \cdot \beta_{t t} \cdot t^{2}+1 / 2 \cdot \beta_{K K}\left(\ln K_{i t}\right)^{2} \\
& +1 / 2 \cdot \beta_{L L}\left(\ln L_{i t}\right)^{2}+1 / 2 \cdot \beta_{H H}\left(\ln H_{i t}\right)^{2} \\
& +\beta_{K t}\left[\left(\ln K_{i t}\right) \cdot t\right]+\beta_{K L}\left[\left(\ln K_{i t}\right) \cdot\left(\ln L_{i t}\right)\right] \\
& +\beta_{K H}\left[\left(\ln K_{i t}\right) \cdot\left(\ln H_{i t}\right)\right]+\beta_{L t}\left[\left(\ln L_{i t}\right) \cdot t\right] \\
& +\beta_{L H}\left[\left(\ln L_{i t}\right) \cdot\left(\ln H_{i t}\right)\right]+\beta_{H t}\left[\left(\ln H_{i t}\right) \cdot t\right] \\
& +v_{i t}-u_{i t}
\end{aligned}
$$

As proposed by Garcia, Souza and Pires (2008), no coefficients are included to control for heterogeneity between countries. Given the high correlation that exists between the dummy variables and the explanatory variables, that procedure generally distorts the estimates of technical efficiency and technological progress. It is

21 Although the total number of observations is 585, owing to the lack of data on the capital endowment in some countries, the number of effective observations in the panels varies between 570 and 547. 
therefore assumed that any heterogeneity in the industrial sectors of the sample countries can be captured through the model's explanatory variables and the technical inefficiency component.

The trend of TFP is estimated using equation (8). As there is no information on labour remuneration by skill level in the WIOD, the expression was simplified to encompass the total variation in hours worked, without prejudice to the concepts defined in the foregoing section. Technological progress and the elasticities of value added with respect to each factor of production are given by equations (12) and (13). By construction, the elasticities and technical progress of a given activity sector vary through time and across countries. The variation in allocative efficiency was obtained as a residual — by definition, that measure is the variation in TFP, having discounted technical progress, technical efficiency and economies of scale.

$$
\begin{gathered}
T C=\frac{\dot{B}_{i t}}{B_{i t}}=\beta_{t}+\beta_{t t} \cdot t \\
+\beta_{t K} \cdot K_{i t}+\beta_{t H} \cdot H_{i t}+\beta_{t L} \cdot L_{i t} \\
\varepsilon_{j}=\beta_{j}+\beta_{j K} \cdot K_{i t}+\beta_{j H} \cdot H_{i t}+\beta_{j L} \cdot L_{i t}+\beta_{j t} \cdot t, \\
j=K, H, L
\end{gathered}
$$

Table 5 reports on the estimations of the coefficients of the production frontiers of the 14 industrial sectors for the 40 countries in the sample between 1995 and 2009. In nine of the 14 sectors the variance of the error term $u_{i t}$ is significantly different from zero, which indicates productive inefficiency. In the other sectors, inefficiency is relatively minor, and random deviations from the production frontier predominate. As the variance of $u_{i t}$ tends to zero in the model of the machinery and equipment sector, it was estimated using oLs.

Most of the coefficients are significantly different from zero at the $10 \%$ significance level in all models, which shows that the translog model is appropriate as a generic specification of the frontiers. Moreover, the presence of non-significant coefficients is foreseen in this type of analysis, since the number of observations (maximum 570) is relatively small for the set of parameters to be estimated (14).

\section{Results}

Based on the foregoing estimations, the mean elasticities of the factors of production were firstly calculated in each of the 14 industrial sectors of Brazil and Mexico, along with the average rate of technological progress. Those data were augmented by the estimations of technical efficiency to evaluate the trend of TFP and its components in the two countries between 1995 and 2009. Table 6 shows the estimations for each of the industries in Mexico and Brazil.

As can be seen, the patterns of capital accumulation and the trend of productivity differ greatly between the two countries. In nearly all industrial sectors, capital accumulation rates are higher in Brazil than in Mexico. A similar pattern can be seen in the use of skilled labour, as employment growth is higher in Brazil. This trend is partly offset by a larger reduction in unskilled employment in Brazil than in Mexico, which indicates a more intensive rate of substitution of labour by capital and human capital in Brazil, probably reflecting the sharp rise in labour costs in that country. According to WIOD data, the average value of real wages 22 in Brazil grew by $3.1 \%$ per year between 1995 and 2009, compared to a reduction of $0.9 \%$ per year in Mexico.

The counterpart of the slower pace of factor accumulation in Mexico was more vigorous growth of TFP. Mexico's industries generally recorded higher TFP growth rates, except for the textile products, chemicals and machinery and equipment industries.

In terms of the components of TFP, the situation is quite varied. In Mexico, technological progress between 1995 and 2009 was positive in all industrial sectors except for five. In Brazil, however, eight of the 14 sectors posted negative rates of technological progress, probably owing to the recomposition of production within each sector, involving the retreat of higher value added product lines and specialization in products of lower technological content. The reduction in manufacturing industry value added per hour worked, mentioned in the introduction to this article, corroborates that idea. Also important is the influence of the general economic situation in 2009, the last year of the comparison, because the global recession hit the prices of several industrial products, with effects on industrial value added.

The trend of technical efficiency is also worse in Brazil than in Mexico in 10 of the 14 sectors analysed. The situation is even more serious in terms of economies of scale: as shown in table 6, Brazil lags behind Mexico in 11 out of the 14 industrial sectors. This is probably affected by Mexico's trade integration with the United States and Canada, which considerably expands the scale of businesses in the country. In the case of allocative

\footnotetext{
22 Variation over and above the inflation rate (consumer prices).
} 


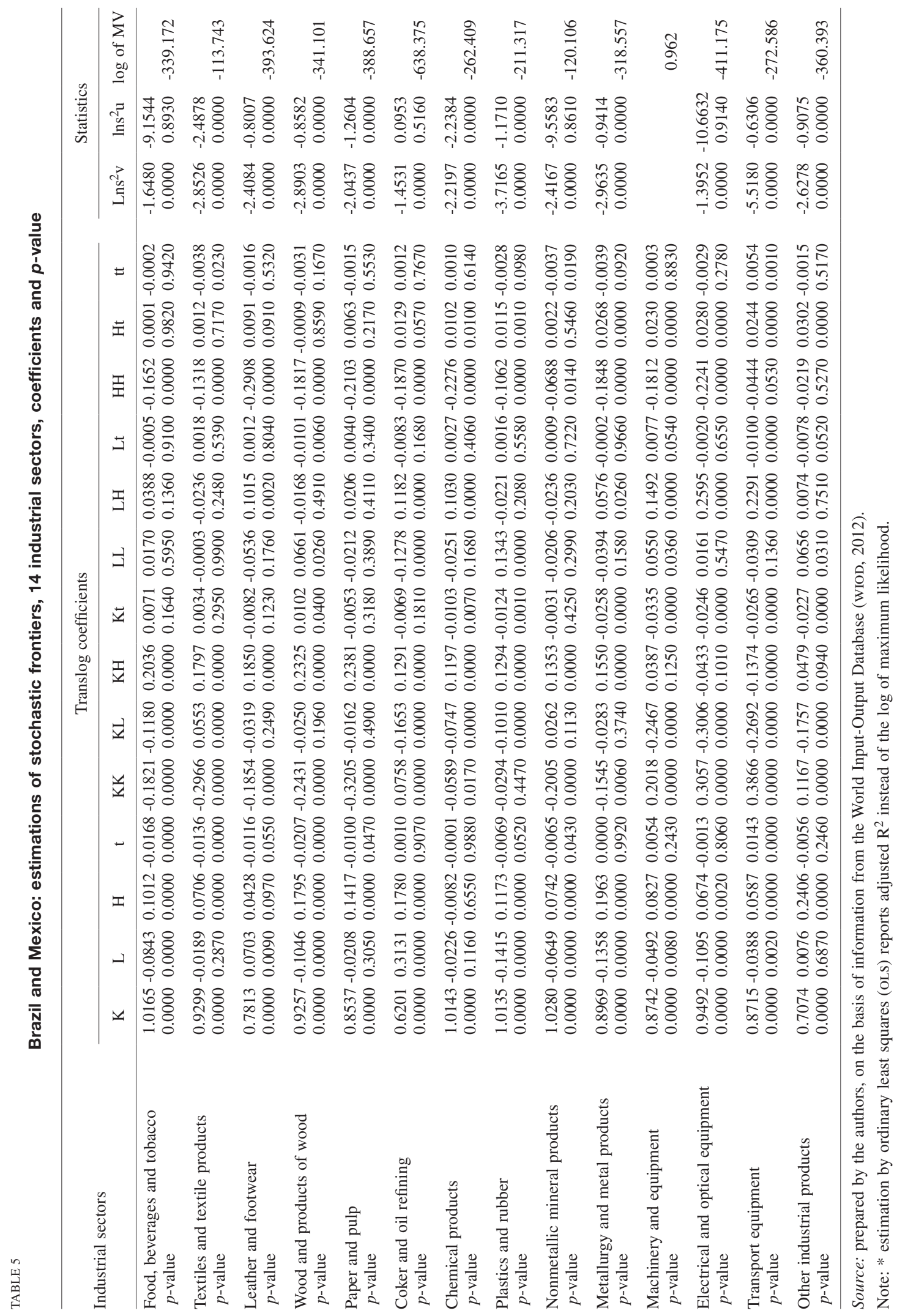


TABLE 6

Brazil and Mexico: growth, factor accumulation and productivity trend, 14 industrial sectors from 1995 to 2009

(Percentages, annual average)

\begin{tabular}{|c|c|c|c|c|c|c|c|c|c|}
\hline \multirow{2}{*}{ Industrial sectors } & \multirow{2}{*}{$\mathrm{Y}$} & \multicolumn{3}{|c|}{ Factor accumulation } & \multicolumn{5}{|c|}{ Productivity trend } \\
\hline & & $\mathrm{K}$ & $\mathrm{L}$ & $\mathrm{H}$ & PTF & $\mathrm{TC}$ & $\mathrm{TE}$ & SE & $\mathrm{AE}$ \\
\hline \multicolumn{10}{|c|}{ Brazil } \\
\hline Food, beverages and tobacco & 2.1 & 6.3 & -0.5 & 6.3 & -2.1 & -0.4 & 0.0 & -1.4 & -0.3 \\
\hline Textiles and textile products & -0.5 & 1.2 & -2.3 & 4.5 & -1.3 & 0.1 & -0.8 & 0.1 & -0.7 \\
\hline Leather and footwear & -2.0 & 6.9 & -1.2 & 5.6 & -4.8 & 0.2 & -6.0 & -0.8 & 1.8 \\
\hline Wood and products of wood & -1.7 & 11.8 & -4.3 & 4.2 & -7.1 & -2.9 & -8.9 & 0.6 & 4.1 \\
\hline Paper and pulp & 2.7 & 19.1 & -4.2 & 4.4 & -6.6 & -0.5 & -4.9 & -3.3 & 2.1 \\
\hline Coke and refined petroleum & 5.5 & 18.4 & -0.5 & 8.1 & -10.8 & -1.9 & -6.8 & -3.2 & 1.1 \\
\hline Chemical products & 5.5 & 6.9 & -4.1 & 4.5 & 1.7 & 0.8 & -0.6 & -0.3 & 1.8 \\
\hline Plastics and rubber & -0.6 & 7.8 & -1.2 & 7.4 & -5.4 & -0.6 & -7.6 & 0.1 & 2.6 \\
\hline Nonmetallic mineral products & 1.7 & 2.2 & -2.6 & 6.0 & 0.0 & -0.5 & 0.0 & 0.1 & 0.5 \\
\hline Metallurgy and metal products & 2.0 & 8.9 & -2.0 & 6.6 & -4.0 & -1.0 & -6.1 & -0.8 & 3.9 \\
\hline Machinery and equipment & 3.8 & 6.1 & -0.8 & 7.8 & -0.2 & 0.1 & 0.0 & -1.5 & 1.1 \\
\hline Electrical and optical equipment & 1.6 & 3.1 & -1.5 & 6.0 & -1.2 & 0.1 & 0.0 & -0.9 & -0.4 \\
\hline Transport equipment & 5.1 & 13.0 & -0.7 & 6.8 & -0.4 & -2.6 & -5.9 & -4.3 & 12.4 \\
\hline Other industrial products & 2.3 & 2.9 & -3.0 & 4.4 & 0.6 & 0.9 & -1.0 & -1.1 & 1.7 \\
\hline \multicolumn{10}{|c|}{ Mexico } \\
\hline Food, beverages and tobacco & 2.7 & -0.4 & 1.6 & 2.8 & 2.4 & -1.0 & 0.0 & 0.1 & 3.3 \\
\hline Textiles and textile products & -0.1 & 2.1 & 0.7 & 4.2 & -2.1 & -0.6 & -0.6 & 0.2 & -1.0 \\
\hline Leather and footwear & -0.6 & -1.0 & -1.5 & 1.3 & 0.1 & -0.1 & 0.2 & 0.1 & -0.1 \\
\hline Wood and products of wood & -0.2 & -0.6 & -1.9 & 1.4 & 0.2 & -3.6 & 2.3 & 0.0 & 1.6 \\
\hline Paper and pulp & 1.9 & 0.9 & 0.7 & 1.3 & 0.9 & 0.4 & 0.3 & 0.0 & 0.3 \\
\hline Coker and oil refining & -0.4 & -0.3 & -1.9 & -1.1 & -0.4 & 1.2 & -0.7 & 0.0 & -0.8 \\
\hline Chemical products & 2.1 & 1.3 & -2.0 & 1.3 & 1.0 & 1.8 & -0.1 & 0.0 & -0.7 \\
\hline Plastics and rubber & 2.1 & 2.7 & -0.5 & 2.8 & -0.1 & 1.4 & -1.4 & 0.0 & -0.1 \\
\hline Nonmetallic mineral products & 2.2 & 0.5 & -1.3 & 3.0 & 1.7 & -0.6 & 0.0 & 0.0 & 2.3 \\
\hline Metallurgy and metal products & 2.2 & 0.4 & -1.4 & 1.7 & 1.7 & 1.6 & -0.1 & 0.0 & 0.3 \\
\hline Machinery and equipment & 1.3 & 2.6 & 0.0 & 2.4 & -0.8 & 5.7 & 0.0 & -0.2 & -6.3 \\
\hline Electrical and optical equipment & 1.7 & 2.9 & -1.9 & 4.0 & -0.6 & 5.1 & 0.0 & -0.1 & -5.7 \\
\hline Transport equipment & 4.0 & 4.0 & 2.2 & 2.2 & 0.8 & 1.8 & -0.1 & -0.3 & -0.7 \\
\hline Other industrial products & 3.0 & -0.5 & 4.2 & 1.6 & 2.1 & 2.7 & -0.3 & -0.2 & -0.1 \\
\hline
\end{tabular}

Source: prepared by the authors, on the basis of information from the World Input-Output Database (WIOD, 2012).

efficiency, while Brazil recorded increases in nearly all manufacturing industries, there were decreases in nine sectors in Mexico.

The productivity indices of each country (Brazil and Mexico) in each of the 14 industrial sectors are shown in table 7, estimated in relation to the sample base year of 1995. The values for that year were subjected to the TFP variations estimated on the basis of table 6; so the resulting indices express the historical differences and recent trend of the 14 industrial sectors in the two countries.

The data of table 7 show that there were few productivity differences in 1995 . In general, productivity levels in Brazilian industries were higher than those of their Mexican counterparts (in 10 of the 14 sectors). Only in the "wood and products of wood" and "plastics and rubber" sectors does Mexico surpass Brazil. In two other sectors (textile products and chemicals), the differences were small. By 2009, however, the situation had changed drastically. Only four sectors of Brazilian industry maintained factor productivity levels that were substantially above those of Mexican industries: textiles and textile products; chemical products; machinery and equipment, and transport equipment. In the other industries, Mexico's TFP greatly surpassed that of Brazil in 2009 . 
TABLE 7

Brazil and Mexico: productivity indices, 14 industrial sectors 1995 and 2009

\begin{tabular}{|c|c|c|c|c|c|c|}
\hline \multirow{2}{*}{ Industrial sectors } & \multicolumn{3}{|c|}{1995} & \multicolumn{3}{|c|}{2009} \\
\hline & Brazil (A) & $\operatorname{Mexico}(\mathrm{B})$ & $(\mathrm{A} / \mathrm{B})$ & Brazil (A) & Mexico (B) & $(\mathrm{A} / \mathrm{B})$ \\
\hline Textiles and textile products & 81.0 & 83.0 & 0.976 & 81.0 & 83.0 & 0.976 \\
\hline Leather and footwear & 65.7 & 63.3 & 1.038 & 65.7 & 63.3 & 1.038 \\
\hline Wood and products of wood & 51.1 & 57.8 & 0.885 & 51.1 & 57.8 & 0.885 \\
\hline Coker and oil refining & 53.7 & 42.3 & 1.269 & 53.7 & 42.3 & 1.269 \\
\hline Chemical products & 79.4 & 81.0 & 0.980 & 79.4 & 81.0 & 0.980 \\
\hline Plastics and rubber & 77.6 & 83.1 & 0.934 & 77.6 & 83.1 & 0.934 \\
\hline Nonmetallic mineral products & 99.3 & 99.3 & 1.000 & 99.3 & 99.3 & 1.000 \\
\hline Metallurgy and metal products & 66.7 & 58.6 & 1.138 & 66.7 & 58.6 & 1.138 \\
\hline Machinery and equipment & 100.0 & 100.0 & 1.000 & 100.0 & 100.0 & 1.000 \\
\hline Electrical and optical equipment & 99.6 & 99.6 & 1.000 & 99.6 & 99.6 & 1.000 \\
\hline Transport equipment & 78.8 & 61.6 & 1.279 & 78.8 & 61.6 & 1.279 \\
\hline
\end{tabular}

Source: prepared by the authors, on the basis of information from the World Input-Output Database (WIOD, 2012).

\section{IV}

\section{Foreign trade and productivity}

The analyses reported in the previous section show that the manufacturing-industry productivity trend was generally more favourable in Mexico than in Brazil, such that in a few years Brazil's relative advantage was reversed. The input requirements needed for production decreased in eight of the 14 manufacturing sectors in Mexico, while they increased in the case of Brazil. Apart from one sector, the growth of requirements was less in Mexico, indicating a considerable saving in the use of intermediate goods and services.

From the TFP standpoint, the results revealed a large increase in just three industrial sectors of the Brazilian economy (textiles, chemicals, and machinery and equipment). In the other 11 sectors, productivity growth was greater in Mexico.

In addition to the positive trend of TFP, in seven sectors of Mexican manufacturing industry (food and beverages, leather and footwear, products of wood, paper and pulp, nonmetallic minerals, metallurgy, and transport equipment) there was also a reduction in input requirements. These two processes combine to enhance industrial competitiveness. In the chemicals and other industrial products sectors, the greater input requirement is offset by an increase in TFP. In the case of Brazil, the productivity trend is quite negative: input requirements increased in all manufacturing sectors, except for leather and footwear; and TFP decreased in all of them, except for chemicals, nonmetallic minerals, and other industrial products.

A relevant fact revealed by the analyses is that the increase in imported goods and services requirements in Mexican manufactures was compensated for by a reduction in domestic goods and services requirements. This suggests that, at least in the case of Mexico, trade liberalization had a decisive influence on the productivity trend - as is frequently claimed in the literature on productivity in Latin America- Bandeira and Garcia (2002), for example, suggest that trade liberalization in the Latin American economies had positive effects on investment and economic growth in the region in the 1990s. Hay (2001); Cavalcanti and Rossi (2003), and Schor (2004) use different methods to analyse the productivity of Brazil's manufacturing industry, and they report substantial TFP gains linked to the rapid reduction in import quotas in the 1990s. Moreover, the studies by Weiss (1992); İşcan (1998), and Guillermo and Tanka (2007) reveal the effects of trade liberalization on the efficiency of Mexico's manufacturing industry at different points in time, particularly in the 1980s and 1990s.

Statistics on the composition of the demand for manufactured products in Brazil and Mexico, and how this relates to the productivity trend, corroborate this 
view. Table 8 shows the share of imports in total demand in the Brazilian in Mexican economies in 1995 and 2009 , by manufacturing industry sector. The statistics, taken from the WIOD, indicate the degree of penetration of imports of industrial goods in domestic demand, considering its two components: (i) final demand, consisting of consumption and investment by families, public administrations and non-profit institutions, and (ii) intermediate consumption, consisting of demand for goods and services by firms and the government.

The data of table 8 show that, despite a considerable increase in Brazilian imports, the manufactured goods markets in that country were relatively little affected. Imports, which represented $11.1 \%$ of final demand for manufactured goods in 1996, were just $11.6 \%$ in 2009.
Imports of manufactured goods to satisfy intermediate demand by firms in all sectors of economic activity, grew from $10.6 \%$ in 1995 to $12.7 \%$ in 2009 . In other words, despite trade liberalization, imports satisfied a relatively small proportion of the final and intermediate demand for Brazil's manufactures.

In Mexico, the situation was very different. As a result of its accession to the North American Free Trade Agreement (NAFTA) in 1992, the share of imports in the composition of final and intermediate demand for manufactured goods grew by much more. That treaty between Mexico, the United States and Canada set a 15 -year period for the total elimination of tariff barriers between the three countries; and this expired in 2007. In that context, the import content in the final demand for

Brazil and Mexico: share of imports in final, intermediate and total demand, 1995 and 2009

(Percentages)

\begin{tabular}{|c|c|c|c|c|c|c|}
\hline & \multicolumn{3}{|c|}{ Brazil } & \multicolumn{3}{|c|}{ Mexico } \\
\hline & Intermediate & Final & Total & Intermediate & Final & Total \\
\hline \multicolumn{7}{|c|}{1995} \\
\hline Food, beverages and tobacco & 3.8 & 9.2 & 7.3 & 13.8 & 4.2 & 6.0 \\
\hline Textiles and textile products & 9.7 & 2.6 & 5.8 & 26.9 & 51.0 & 37.4 \\
\hline Leather and footwear & 6.0 & 4.1 & 4.7 & 3.9 & 18.2 & 12.2 \\
\hline Wood and products of wood & 1.4 & 6.9 & 1.7 & 16.8 & 2.9 & 13.7 \\
\hline Paper and pulp & 7.5 & 4.8 & 6.9 & 27.1 & 15.8 & 24.7 \\
\hline Coker and oil refining & 7.5 & 7.0 & 7.3 & 11.9 & 6.9 & 9.4 \\
\hline Chemical products & 22.3 & 7.8 & 17.5 & 39.6 & 9.2 & 26.6 \\
\hline Plastics and rubber & 7.7 & 15.2 & 8.7 & 56.1 & 21.7 & 47.5 \\
\hline Nonmetallic mineral products & 4.0 & 6.1 & 4.2 & 16.4 & 1.7 & 11.3 \\
\hline Metallurgy and metal products & 6.8 & 9.0 & 7.1 & 41.8 & 11.7 & 35.2 \\
\hline Machinery and equipment & 19.5 & 23.4 & 22.2 & 81.3 & 70.1 & 74.3 \\
\hline Electrical and optical equipment & 20.5 & 19.1 & 19.7 & 79.4 & 58.4 & 72.4 \\
\hline Transport equipment & 13.5 & 14.3 & 14.0 & 52.0 & 9.9 & 29.2 \\
\hline Other industrial products & 4.3 & 5.6 & 5.3 & 22.5 & 8.5 & 12.7 \\
\hline Total manufactures & 10.6 & 11.1 & 10.9 & 41.9 & 17.1 & 30.0 \\
\hline \multicolumn{7}{|c|}{2009} \\
\hline Food, beverages and tobacco & 3.2 & 4.0 & 3.7 & 94.0 & 8.0 & 23.5 \\
\hline Textiles and textile products & 11.8 & 3.9 & 7.2 & 89.6 & 38.7 & 65.3 \\
\hline Leather and footwear & 2.3 & 6.7 & 5.7 & 94.7 & 28.4 & 51.7 \\
\hline Wood and products of wood & 1.5 & 3.3 & 1.6 & 60.4 & 6.8 & 49.8 \\
\hline Paper and pulp & 5.0 & 2.1 & 4.3 & 65.3 & 16.9 & 55.7 \\
\hline Coker and oil refining & 7.6 & 7.3 & 7.5 & 58.4 & 21.9 & 41.6 \\
\hline Chemical products & 23.0 & 12.6 & 19.7 & 88.1 & 25.1 & 66.1 \\
\hline Plastics and rubber & 9.5 & 22.3 & 10.6 & 86.6 & 58.3 & 81.6 \\
\hline Nonmetallic mineral products & 4.1 & 10.8 & 4.4 & 35.9 & 2.8 & 27.4 \\
\hline Metallurgy and metal products & 8.6 & 7.6 & 8.5 & 81.5 & 24.6 & 73.3 \\
\hline Machinery and equipment & 23.6 & 19.0 & 20.2 & 95.6 & 86.0 & 88.9 \\
\hline Electrical and optical equipment & 29.4 & 33.3 & 31.5 & 96.0 & 74.1 & 89.0 \\
\hline Transport equipment & 18.4 & 11.6 & 14.3 & 88.8 & 55.1 & 68.4 \\
\hline Other industrial products & 8.5 & 5.2 & 5.9 & 65.9 & 17.6 & 35.0 \\
\hline Total manufactures & 12.7 & 11.6 & 12.2 & 81.9 & 29.6 & 57.0 \\
\hline
\end{tabular}

Source: prepared by the authors, on the basis of information from the World Input-Output Database (WIOD, 2012). 
manufactured goods grew from $17.1 \%$ in 1995 to $29.6 \%$ in 2009; and the penetration of imports in intermediate demand for manufactured goods increased by 40 percentage points, from $41.9 \%$ to $81.9 \%$ between 1995 and 2009. Most of that growth was based specifically on products originating in the NAFTA area, which includes two highly industrialized economies.

Considering the data from the 14 industrial sectors in Brazil and Mexico, the reduction in input requirements recorded between 1995 and 2009 seems to be negatively correlated with the increased share of imports in total demand, as shown in figure 1. Considering the average of the sectors, the larger the increase in imports in the total demand for manufactured goods, the relatively larger were the reductions in requirements to produce those manufactured goods in each of the two countries. This shows that the greater relative importance of imports could have contributed to the cost reduction and, hence, to the more efficient production of manufactured goods. ${ }^{23}$

The analyses performed in this article reveal the different paths followed by Brazilian and Mexican manufacturing industries between 1995 and 2009. While Mexican industry consolidated its position with a significant productivity increase, despite the reduction in the share of manufacturing in GDP and in the total demand for manufactured goods, Brazilian industry experienced an absolute and relative productivity loss,

23 A similar relation exists between increases in the import share of demand between 1995 and 2009 and the trend of TFP in the 14 industrial sectors of Mexico and Brazil. The linear correlation coefficient between the two variables is $50.1 \%$.

FIGURE 1

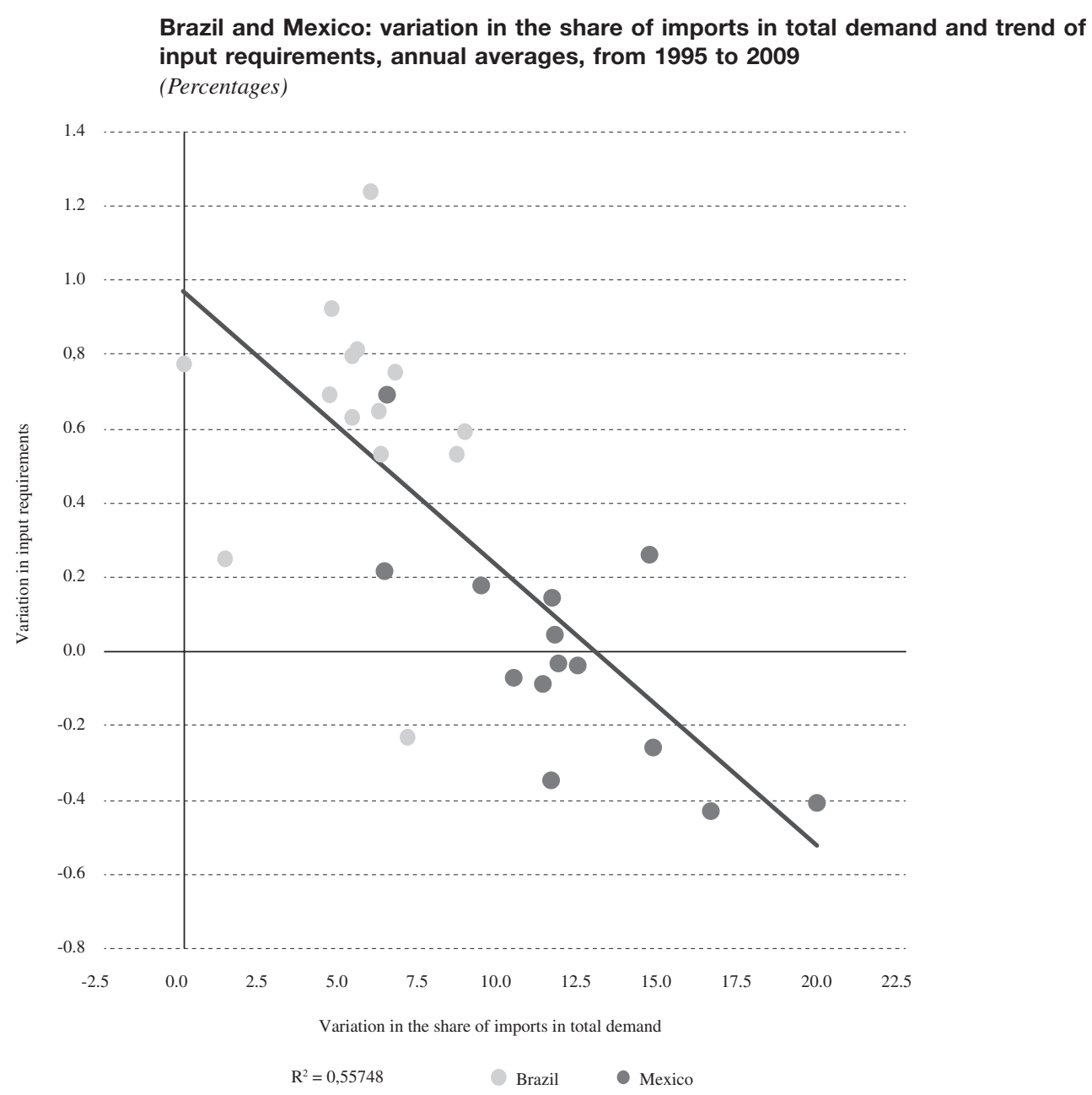

Source: prepared by the authors, on the basis of information from the World Input-Output Database (WIOD, 2012). 
along with a rise in costs. The fact that manufactured goods markets in that country are more isolated from foreign trade could have contributed to the weak productivity performance. As a counterpart, final demand for manufactured goods grew by 25.4 percentage points less in Brazil than in Mexico between 1995 and 2009.
Accordingly, the results reported in this article suggest a future need for more in-depth research into the pattern of consumption and foreign trade in manufactured goods in the two economies, and a study of the effects of the changes in industrial productivity on economic growth and welfare in the two countries.

\section{Bibliography}

Bandeira, A.C. and F. Garcia (2002), "Reforms and growth in Latin America", CEPAL Review, No. 77 (LC/G.2180-P), Santiago, Chile, August

Carter, A.P. (1980), "Changes in input-output structures since 1972", Data Resources Interindustry Review.

(1967), "Changes in the structure of the American economy, 1947 to 1958 and 1962", The Review of Economics and Statistics, vol. 49, No. 2, Cambridge, Massachusetts, The Mाт Press, May.

Cavalcanti, P. and J. Rossi (2003), "New evidence from Brazil on trade liberalization and productivity growth", International Economic Review, vol. 44, No. 4, Wiley, November.

Feldman, S.J., D. McClain and K. Palmer (1987), "Sources of structural change in the United States 1963-78. An input-output perspective", The Review of Economics and Statistics, vol. 69, No. 3, Cambridge, Massachusetts, The miт Press, August.

Garcia, F., R.C. Souza and J.O. Pires (2008), "Technical change: it should be positive and make sense!", Economics Letters, vol. 100, No. 3, Amsterdam, Elsevier.

Guillermo, S. and B. Tanka (2007), "Measuring total factor productivity growth in Mexican manufacturing: the story before and after trade liberalization”, Ensayos sobre Política Económica, vol. 25, No. 53, Bogota, Bank of the Republic.

Hay, D. (2001), "The post-1990 Brazilian trade liberalization and the performance of large manufacturing firms: productivity, market share and profits", The Economic Journal, vol. 111, No. 473, Wiley, July.

İşcan, T. (1998), "Trade liberalization and productivity: a panel study of the Mexican manufacturing industry", The Journal of Development Studies, vol. 34, No. 5, Taylor \& Francis.

Katz, J. (2000), "Structural change and labor productivity growth in Latin American manufacturing industries 1970-96", World Development, vol. 28, No. 9, Amsterdam, Elsevier.

Kneller, R. and A. Stevens (2003), "The specification of aggregate production function in the presence of inefficiency", Economics Letters, vol. 81, No. 2, Amsterdam, Elsevier.
Kumbhakar, S.C., M. Denny and M. Fuss (2000), "Estimation and decomposition of productivity change when production is not efficient", Econometric Reviews, vol. 19, No. 4, Taylor $\&$ Francis.

Kumbhakar, S.C. and H. Wang (2005), "Estimation of growth convergence using a stochastic production frontier approach", Economics Letters, vol. 88, No. 3, Amsterdam, Elsevier.

Lahr, M.L. and E.E. Dietzenbacher (eds.) (2001), Input-Output Analysis: Frontiers and Extensions, Houdmills, Palgrave.

Leontief, W. (1951), The Structure of the American Economy, New York, Oxford University Press.

Mesquita, M. (2007), "Fear of China: is there a future for manufacturing in Latin America?", World Development, vol. 35, No. 3, Amsterdam, Elsevier.

Miller, R. and P. Blair (2009), Input-Output Analysis, Cambridge, Cambridge University Press.

Moreira, M.M. (2007), "Fear of China: is there a future for manufacturing in Latin America?", World Development, vol. 35, No. 3, Amsterdam, Elsevier.

Pires, J. and F. Garcia (2012), "Productivity of nations: a stochastic frontier approach to TFP decomposition", Economics Research International, Hindawi Publishing Corporation.

Schor, A. (2004), "Heterogeneous productivity response to tariff reduction. Evidence from Brazilian manufacturing firms", Journal of Development Economics, vol. 75, No. 2, Amsterdam, Elsevier.

Solow, R.M. (1957), "Technical change and the aggregate production function", Review of Economics and Statistics, vol. 39.

Weiss, J. (1992), "Trade policy reform and performance in manufacturing: Mexico 1975-88", The Journal of Development Studies, vol. 29, No. 1, Taylor \& Francis.

WIOD (World Input-Output Database) (2012), The World Input-Output Database: Contents, Sources and Methods, M. Timmer (ed.), April [online] www.wiod.org/database. 